\title{
Análises benchmark de jogos de tabuleiro com enfoque narrativo a partir da tétrade elementar de Jesse Schell
}

\author{
Benchmark analysis of narrative- \\ driven board games using Jesse \\ Schell's elemental tetrad
}

\author{
Marcelle de Lemos Uliano ${ }^{[1]}$, \\ Mônica Lima de Faria (orientadora) ${ }^{[2]}$
}

\begin{abstract}
Resumo: A partir de um estudo histórico sobre os campos de jogos e narrativa, constatou-se que este diálogo é frequentemente relacionado à ascensão contemporânea dos jogos digitais, ofuscando o importante papel dos jogos de tabuleiro neste cruzamento. Tal reflexão originou o trabalho de conclusão de curso da autora, "Industrial Cases: Design da pré-produção de um jogo de tabuleiro com enfoque narrativo" (2018), no qual buscou-se averiguar a capacidade de jogos de tabuleiro de agirem como meios proporcionadores de experiências narrativas através da concepção de um jogo de tabuleiro com enfoque narrativo. Para dar início ao processo de game design, uma coleta de referências foi realizada através da análise de títulos já existentes, utilizando a tétrade elementar de Schell (2011) e análises benchmark.
\end{abstract}

Palavras-chave: Jogos de tabuleiro. Game design. Narrativa. Tétrade elementar. Análises benchmark.

Abstract: From a historical study on the fields of gaming and narrative, it was found that this dialogue is often related to the contemporary rise of digital games, overshadowing the important role of board games in this intersection. Such reflection origina-

[1] Graduada em Design Gráfico, UFPEL.marcelle.uliano@hotmail.com

[2] Doutora em Comunicação Social, PUCRS.monicalfaria@gmail.com 
ted the author's conclusion work, "Industrial Cases: Design of the pre-production of a board game with a narrative focus" (2018), in which we sought to ascertain the ability of board games to act as means providers of narrative experiences through the design of a board game with a narrative focus. To start the game design process, a collection of references was performed through the analysis of existing titles, using Schell's elementary tetrad (2011) and benchmark analysis.

Keywords: Board games. Game design. Narrative. Elementaltetrad. Benchmarkanalysis.

\section{INTRODUÇÃO}

Este artigo consiste na adaptação de um recorte integrante ao trabalho de conclusão de curso da autora, intitulado "Industrial Cases: Design da pré-produção de um jogo de tabuleiro com enfoque narrativo" (2018). A motivação para a elaboração deste trabalho parte de um estudo teórico sobre a evolução dos campos dos jogos e da narrativa junto à história da humanidade, onde constatou-se que o diálogo entre estes campos é frequentemente relacionado à ascensão contemporânea dos jogos digitais, ofuscando, assim, o papel dos jogos de tabuleiro neste cruzamento. Portanto, objetiva-se averiguar a capacidade de jogos de tabuleiro de agirem como meios proporcionadores de experiências narrativas, por meio da concepção de um jogo de tabuleiro com enfoque narrativo e temáticas de mistério e investigação.

A coleta de referências para o desenvolvimento desta prática projetual foi efetuada através de análises de títulos já existentes, utilizando a tétrade elementar de Jesse Schell (2011) e a metodologia de benchmarking (conceito abordado mais adiante). A apropriação de aspectos dos jogos analisados proporcionou insumos que deram andamento ao processo de game design. Essas análises serão apresentadas neste artigo.

\section{A TÉTRADE ELEMENTAR}

Os jogos de tabuleiro analisados foram esmiuçados a partir da tétrade elementar dos jogos, teoria proposta por Jesse Schell em seu livro "A Arte do Game Design" (2011), representada na figura 1. Por meio da elaboração deste conceito, 
Schell buscou compreender, dividir e classificar os diversos elementos essenciais à formação de todos os jogos.

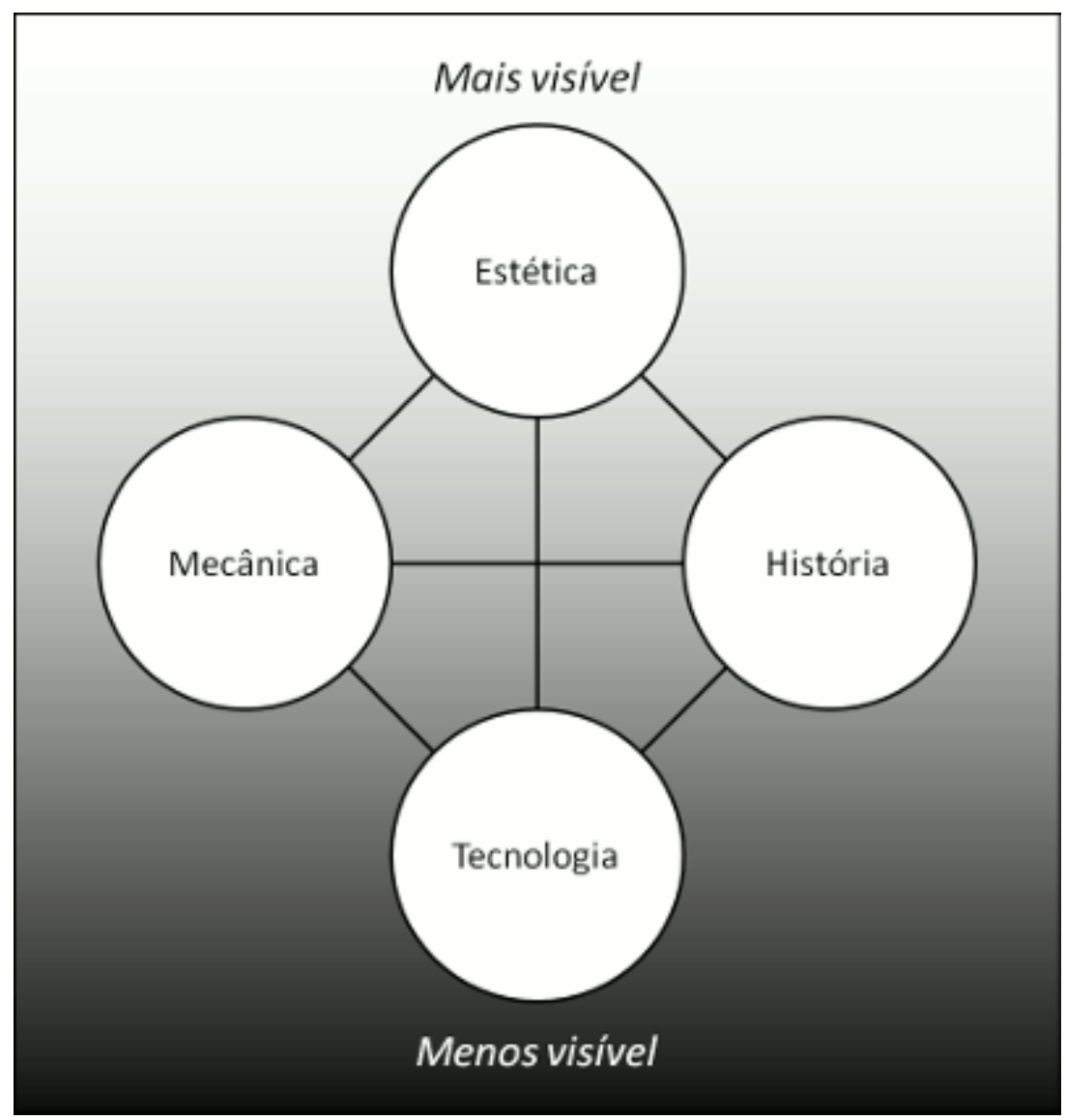

Figura 1 - Tétrade elementar dos jogos. Fonte: SCHELL, 2011, p. 42.

\subsection{MECÂNICA}

A mecânica consiste nos procedimentos e regras de um jogo, incluindo as condições de vitória ou objetivos e o que pode e não pode ser feito dentro do jogo. Segundo Schell (2011, p. 41), "ao escolher um conjunto de funções mecânicas como crucial para o seu jogo, você terá de escolher a tecnologia que pode suportá-lo, a estética que o enfatiza claramente para os jogadores e uma narrativa que permita à (às vezes estranha) mecânica do jogo fazer sentido para os jogadores".

O BoardGameGeek ${ }^{[3]}$ é conhecido como o maior site sobre jogos de tabuleiro existente, contando com cem mil títulos

[13] Disponível em: <https:// boardgamegeek.com/browse/ boardgamemechanic $>$. Acesso em: 22 abr. 2019. 
em sua base de dados. Dentro das funcionalidades oferecidas pelo site, há uma lista que categoriza esses títulos dentre as cinquenta mecânicas mais comuns utilizadas. Alguns exemplos são: rolar dados, manejamento de recursos, memória e contação de histórias, etc.

\subsection{NARRATIVA}

A narrativa é o elemento da tétrade que guia este estudo. Schell (2011, p. 41), entende a narrativa como a sequência de eventos que se desdobram em um jogo. A narrativa em jogos pode se apresentar de forma incorporada ou emergente, sendo que a maioria dos jogos mescla ambas as maneiras ${ }^{[4]}$. Este elemento da tétrade recebeu atenção especial nas análises a seguir.

\subsection{ESTÉTICA}

A estética trata de como o jogo se apresenta visualmente, por meio de cores, aparência, sons, etc. Possui relação direta com a narrativa, pois traz à vida os acontecimentos contados, tornando-os verossímeis. Além disso, este elemento possui papel crucial como proporcionador da imersão do jogador na experiência (SCHELL, 2011, p. 42).

\subsection{TECNOLOGIA}

$\mathrm{Na}$ tecnologia, estão presentes os materiais físicos e interações que tornam o ato de jogar o jogo possível, como papéis, peças, dados ou um computador (SCHELL, 2011, p. 42). No caso dos jogos de tabuleiro, a tecnologia é o aspecto da tétrade elementar que compreende as características do gênero.

\section{ANÁLISES BENCHMARK}

Os jogos em questão também foram estudados de acordo com a análise benchmark (ou benchmarking), que consiste "[...] na procura de pontos de referência com os quais comparar-nos para melhorar o rendimento naquele aspecto que
[14] Para mais informações, consulte o "Capítulo 3.1: Narrativa em jogos" do trabalho de conclusão de curso na íntegra, "Industrial Cases: Design da pré-produção de um jogo de tabuleiro com enfoque narrativo" (ULIANO, 2018, p. 39). 
queremos medir [...]" (CARDIA; GRINGS, 2015, p. 2). Assim, objetivou-se identificar pontos positivos e negativos que serviram de referência do que seguir e do que evitar na criação do jogo de tabuleiro proposto.

Os jogos estudados neste artigo foram jogados, para fins de análise, com alunos dos cursos de Design da Universidade Federal de Pelotas, através dos encontros semanais promovidos pelo Projeto de Ensino de Criação de Jogos de Tabuleiro, coordenado pela prof. Mônica de Faria.

\section{SCOTLAND YARD (2005)}

Scotland Yard é um jogo de dedução e raciocínio que simula processos de investigação. Com inspiração nos romances de Sherlock Holmes, os jogadores assumem o papel do famoso detetive e seu desafio é desvendar os casos propostos, coletando pistas distribuídas pelos locais da cidade de Londres. Os motivos que levaram este jogo a ser escolhido como objeto de análise foram sua temática investigativa, a ambientação baseada em histórias de detetive, os casos narrativos a serem solucionados e a coleta por pistas realizada em sua jogabilidade.

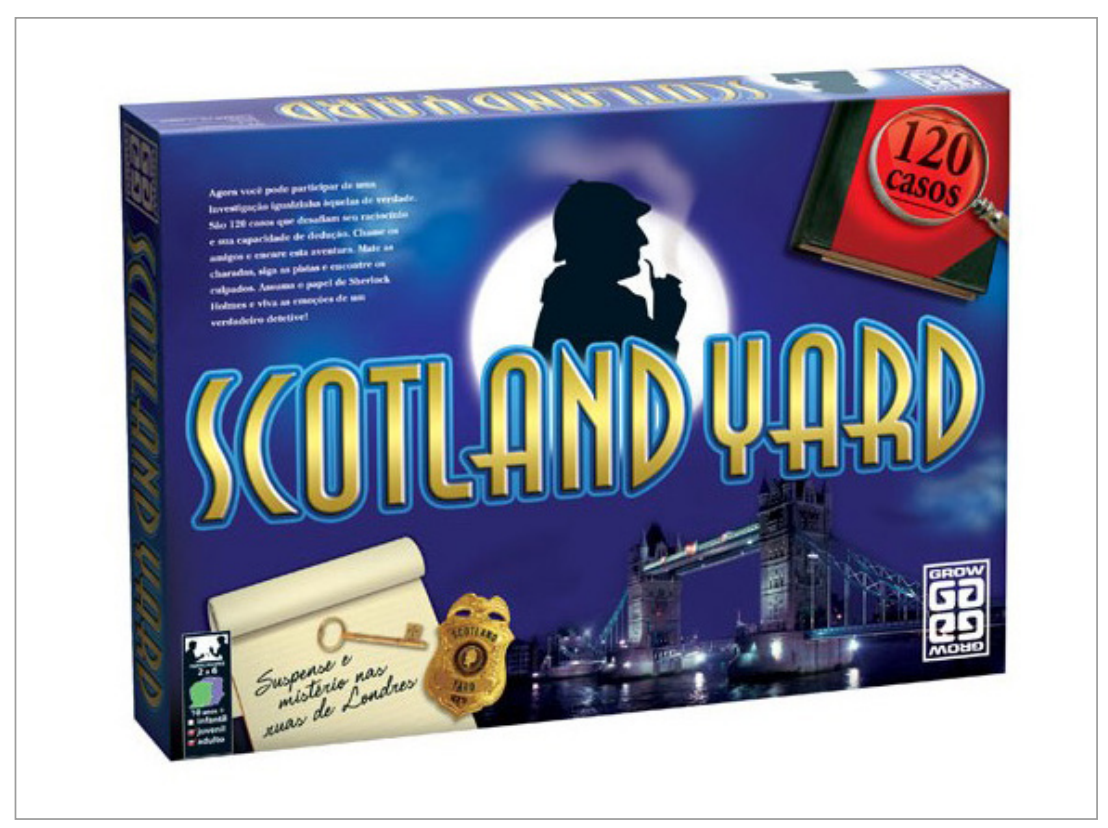

Figura 2 - Caixa do jogo de tabuleiro Scotland Yard (2005). Fonte: <https://i.zst.com.br/ images/jogo-scotland-yardgrow-pho-to4290386-12-19-9. jpg > Acesso em: 20 out. 2018. 
Lançado no Brasil pela empresa Grow em meados dos anos 80, o jogo já foi relançado em diversas versões. Portanto, para esta análise, a versão de 2005 (mostrada na figura 2) foi levada em conta, já que foi a responsável pela popularização do jogo no país.

\subsection{MECÂNICA}

O jogo começa com os jogadores escolhendo um dentre os 120 casos policiais a ser solucionado durante a partida. Um dos jogadores lê o texto da carta do caso em voz alta para que todos conheçam as circunstâncias do caso. Nesta carta, também estão as perguntas que precisam ser resolvidas como objetivo do jogo: qual foi a arma do crime, quem é o assassino, qual foi o motivo, dentre outros.

Após o caso ter sido apresentado, os jogadores, representados por peões, visitam os quatorze locais do tabuleiro para coletar pistas. A movimentação é feita pela rolagem do dado, em sentido horizontal ou vertical.

Ao acessar um dos locais do tabuleiro, o jogador pode ler a pista específica deste local, indicada no verso de cada caso. As pistas estão acessíveis nos cadernos de pistas e os jogadores podem fazer anotações em suas cadernetas, recebidas no início do jogo.

Cada jogador recebe um distintivo da Scotland Yard e uma chave-mestra no início da partida. Caso o jogador visite um dos locais do tabuleiro e considere a sua pista essencial à solução do caso, ele pode utilizar seu distintivo para lacrar o local, impedindo o acesso de outros jogadores a este e atrapalhando suas corridas pelas pistas. Os demais jogadores podem liberar o local lacrado utilizando suas chave-mestras. Após o uso destes itens, o distintivo retorna à delegacia e a chave-mestra retorna ao chaveiro, necessitando que os jogadores se dirijam a estes locais para recuperá-los.

Existem dois tipos de pistas: pistas de informações, que apresentam uma frase que conta uma parte dos eventos ocorridos no crime ou pistas de charada, divididas em partes 
que, reunidas, levam à construção gramatical de uma das respostas do caso. Quando um jogador considera que já possui todas as pistas necessárias para responder às perguntas do caso, ele retorna à Casa do Sherlock Holmes, o ponto inicial do tabuleiro. Assim, ele pode abrir o caderno de respostas e verificar sua solução proposta. Caso a solução proposta pelo jogador esteja correta, ele vence o jogo. Se ocorrer o contrário, o jogador está fora do jogo e a partida continua até algum dos demais jogadores conseguir solucionar o caso.

\subsection{NARRATIVA}

A narrativa é o elemento da tétrade de maior destaque em Scotland Yard. Sua importância é notável pela presença dos 120 casos investigativos que ditam os objetivos do jogo e suas respectivas pistas. A narrativa destes casos é apresentada de forma enxuta devido à quantidade dos mesmos, mas não deixando de serem bem arquitetados. Porém, as pistas nem sempre são eficientes para encontrar a solução do caso por conterem informações vagas - em especial, as pistas do tipo charada, fato que pode frustrar alguns jogadores.

Além disso, a temática de detetive trazida pela inspiração nos romances de Sherlock Holmes promove ainda mais a imersão narrativa. Os locais do tabuleiro a serem visitados durante a coleta de pistas são baseados em locais reais da cidade de Londres, cenário onde as histórias da obra se desenvolvem.

\subsection{ESTÉTICA}

Ao contrário da narrativa, a estética é o elemento da tétrade que recebe menor atenção em Scotland Yard. O uso de montagens fotográficas é a solução mais amplamente utilizada pelo jogo nesta questão, estando presente no tabuleiro, por meio de fotografias dos locais de Londres; nos distintivos e chaves-mestras e na caixa do jogo. Os demais materiais do jogo, como cadernetas, cartas de casos, livros de pistas e panfleto de regras receberam diagramação simples e minimalista. 


\subsection{TECNOLOGIA}

A tecnologia presente no jogo é básica, sendo comum em vários jogos de tabuleiro: os jogadores movimentam os peões pelo tabuleiro através da rolagem de um dado, que dita o número de casas a serem deslocadas no sentido horizontal ou vertical. O tabuleiro conta com duas funcionalidades extras: a estação de carruagens, onde os jogadores podem ir automaticamente para qualquer outro local do tabuleiro e a ponte, que funciona como um atalho, necessitando apenas um ponto do dado para ser atravessada.

Ao entrar em um dos locais do tabuleiro, os jogadores acessam as pistas por meio de um livro de pistas e soluções. A necessidade de acessar tal livro quebra o dinamismo da jogabilidade, já que o jogador precisa procurar a página da pista em questão e, além disso, esta tecnologia depende da honestidade e ética dos jogadores, pois as demais pistas e soluções da mesma página podem ser lidas no momento indevido.

Após ler uma pista de determinado local, o jogador pode fazer anotações na sua Caderneta do Sherlock Holmes (Figura 3). O jogo não inclui lápis ou canetas, necessários para a realização de anotações. O espaço designado para cada anotação na Caderneta é limitado, o que força os jogadores a realizarem anotações resumidas.

\subsection{BENCHMARKING}

Após esmiuçar Scotland Yard a partir da tétrade elementar de Schell, pode-se observar os seguintes pontos positivos do jogo por meio da análise benchmark:

- A expressiva quantia de 120 casos traz um alto valor de rejogabilidade para o jogo;

- Scotland Yard encontra-se em um meio termo de complexidade aceitável entre jogos de tabuleiro casuais (party games) e jogos de tabuleiro hobby ${ }^{[5]}$, sendo considerado um ótimo jogo introdutório a jogos de tabuleiro mais complexos;

[15] Para mais informações, consulte o "Capítulo 2.1: Jogos de tabuleiro" do trabalho de conclusão de curso na íntegra, "Industrial Cases: Design da pré-produção de um jogo de tabuleiro com enfoque narrativo" (ULIANO, 2018, p. 29). 


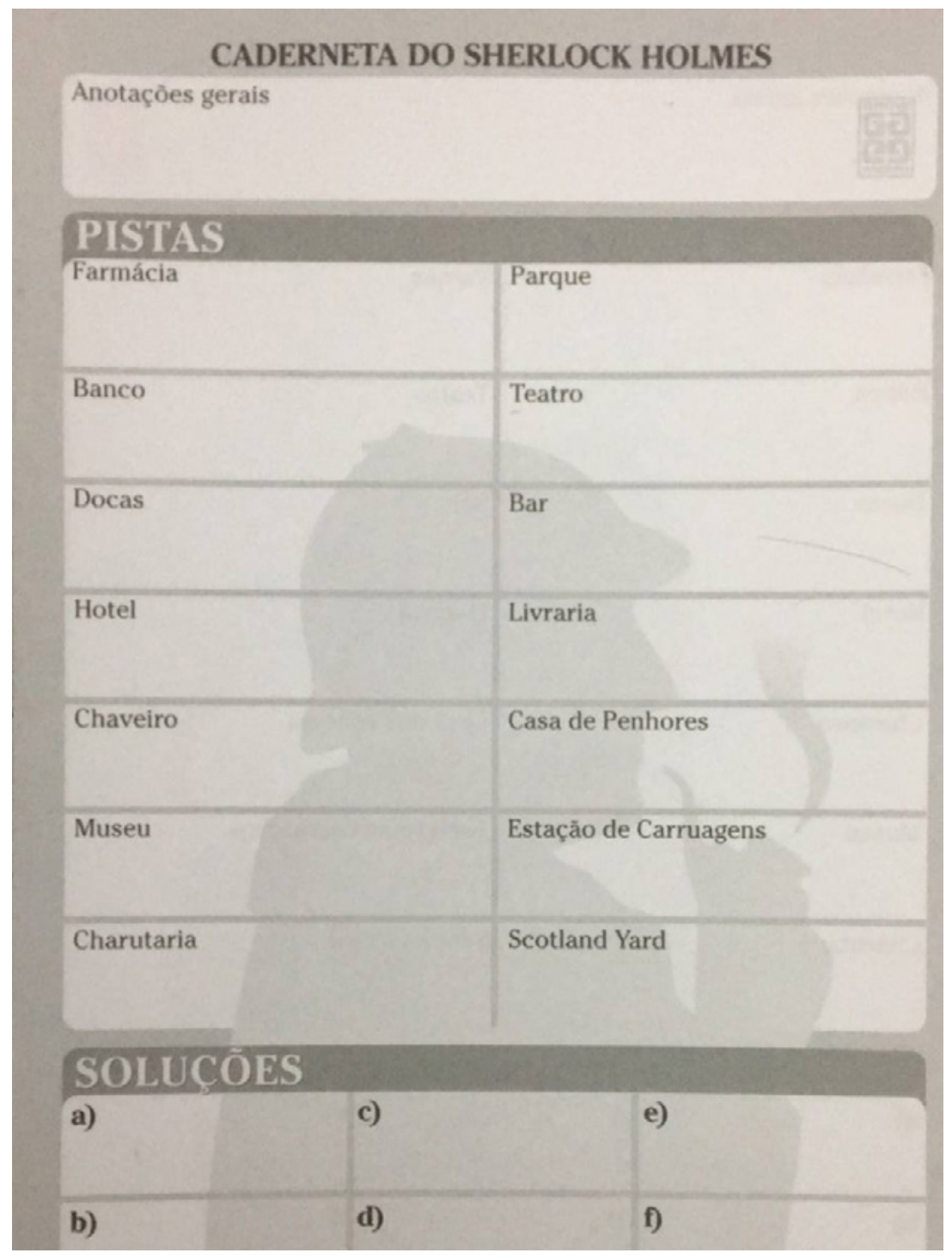

Figura 3 - Caderneta do Sherlock Holmes. Fonte: $<$ https://bit.ly/2W92wYb>. Acesso em 22 abr. 2019.

\begin{tabular}{|c|c|c|}
\hline PISTAS & & \\
\hline Farmácia & & Parque \\
\hline Banco & & Teatro \\
\hline Docas & & Bar \\
\hline Hotel & & Livraria \\
\hline Chaveiro & & Casa de Penhores \\
\hline Museu & & Estação de Carruagens \\
\hline Charutaria & & Scotland Yard \\
\hline SOLUC( & & \\
\hline a) & c) & e) \\
\hline b) & d) & f) \\
\hline
\end{tabular}

- A intensa presença de elementos narrativos e estratégicos no jogo o tornam um desafio divertido e instigante.

Quanto aos pontos negativos do jogo, é possível citar:

- Alguns casos investigativos possuem a dificuldade muito elevada, fazendo com que a maioria dos jogadores não consigam decifrá-los, assim, gerando frustração; 
- As pistas do tipo charada nem sempre são claras o suficiente para que os jogadores entendam o que está sendo revelado - inclusive, algumas dependem de conhecimentos em línguas estrangeiras;

- A maneira como o livro de pistas e soluções foi estruturado facilita que jogadores desonestos trapaceiem, lendo pistas no momento indevido.

Pode-se concluir que o jogo Scotland Yard cumpre com seu objetivo de fornecer uma experiência investigativa de detetives para seus jogadores, todavia, apresentando algumas irregularidades.

\section{T.I.M.E. STORIES}

T.I.M.E. Stories (Figura 4) é um jogo cooperativo que promove experiências narrativas através da exploração de baralhos de cenários, lançado em 2015 pela editora francesa Space Cowboys. Os jogadores assumem o papel de agentes da T.I.M.E., uma agência de viagens no tempo que possui o papel de proteger a humanidade de paradoxos temporais que ameaçam a existência do universo. Esses agentes são enviados para diferentes mundos e realidades com o objetivo de evitar o surgimento destes paradoxos dentro de um prazo limitado. Portanto, T.I.M.E. Stories foi elaborado para servir como uma grande estrutura mecânica capaz de suportar diversas histórias narrativas, não importando suas temáticas, ambientações ou características, o que justifica a sua escolha para a presente análise.

\section{1 MECÂNICA}

$O$ jogo se inicia com os jogadores recebendo um briefing da missão a ser cumprida dentro da base da agência T.I.M.E. Esse momento funciona como um tutorial do jogo, já inserido mecânica e narrativamente por meio da revelação de um baralho de localidade (Figura 5). A revelação de uma localidade consiste na leitura de uma carta de narrativa, que detalha a visão do ambiente em que os agentes se encontram. Além disso, esta 


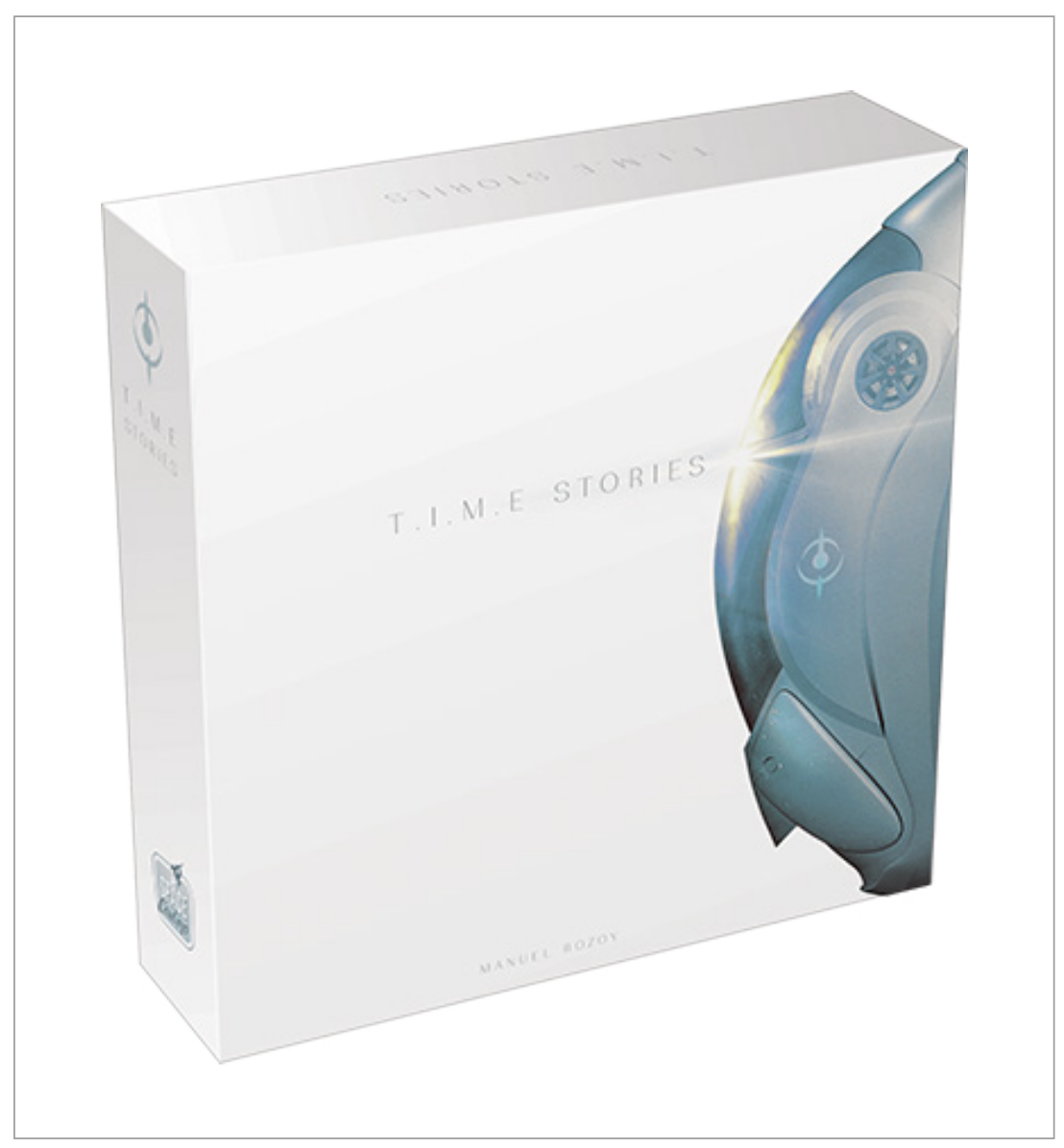

Figura 4 - Caixa do jogo de tabuleiro T.I.M.E. Stories (2015). Fonte: <https://www. spacecowboys.fr/img/games/ time-stories/base--box.png>. Acesso em: 16 abr. 2018

carta especifica a ordem que as demais cartas da localidade devem ser dispostas, formando um panorama ilustrativo.

Neste tutorial, os jogadores recebem o objetivo de completar a missão em questão utilizando o mínimo de tentativas possíveis. A cada tentativa, o grupo dispõe de um número específico de Unidades Temporais (Temporal Units - também chamadas de TUs) para realizar suas ações. Se este medidor chegar a zero, o grupo falha na tentativa, sendo obrigado a recomeçar a missão.

Antes de visitar a primeira localidade da aventura, cada jogador escolhe um personagem, chamado de receptáculo. As cartas de receptáculos apresentam uma ilustração da aparência física do mesmo na frente e, no verso, o número de dados de ação a serem rolados quando o jogador se deparar 


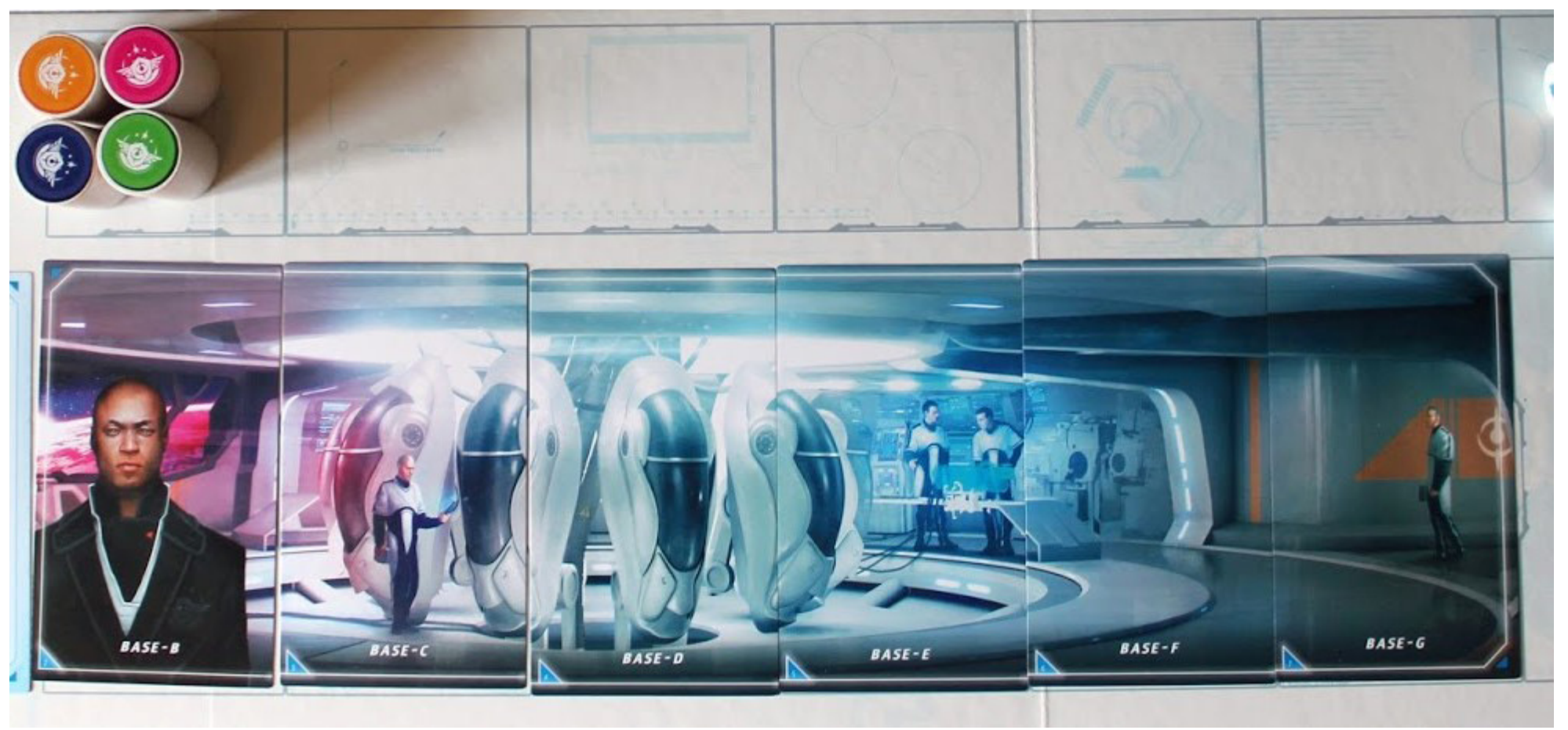

com um teste, além da sua resistência e seus pontos de vida. Em adendo, cada receptáculo possui um poder único, que pode trazer vantagens e desvantagens (Figura 6).

Assim que as cartas da base T.I.M.E. foram lidas e cada jogador selecionou seu receptáculo, deve-se colocar no tabuleiro as cartas da planta, que demonstram o mapa da aventura em que os jogadores se encontram (Figura 7). Um token (peça) representa a localidade em que o grupo está. O grupo sempre precisa se deslocar em conjunto.

Ao chegar em uma localidade, define-se o Capitão do Tempo (Time Captain) da rodada, que é o jogador responsável por ler a carta de narrativa, rolar o dado de TUs e resolver quaisquer discordâncias de decisões entre o grupo. Cada jogador posiciona seu pino colorido acima da carta de localidade que gostaria de examinar. Jogadores podem visitar a mesma carta em conjunto. Logo, eles viram as cartas escoIhidas e leem a informação contida no verso silenciosamente. Como parte do teor narrativo do jogo, é necessário que cada um relate com suas próprias palavras o que leu na carta ao restante do grupo. Além da leitura de uma carta de localidade, pelo preço de uma TU, todos os jogadores podem realizar uma das seguintes ações:
Figura 5 - 0 momento inicial de T.I.M.E. Stories, onde o briefing da missão é apresentado aos agentes. Este momento consiste numa revelação de localidade, servindo tanto como uma introdução narrativa quanto como um tutorial das mecânicas do jogo. Fonte: <https://bit.ly/346ms2w>. Acesso em: 22 abr. 2019. 


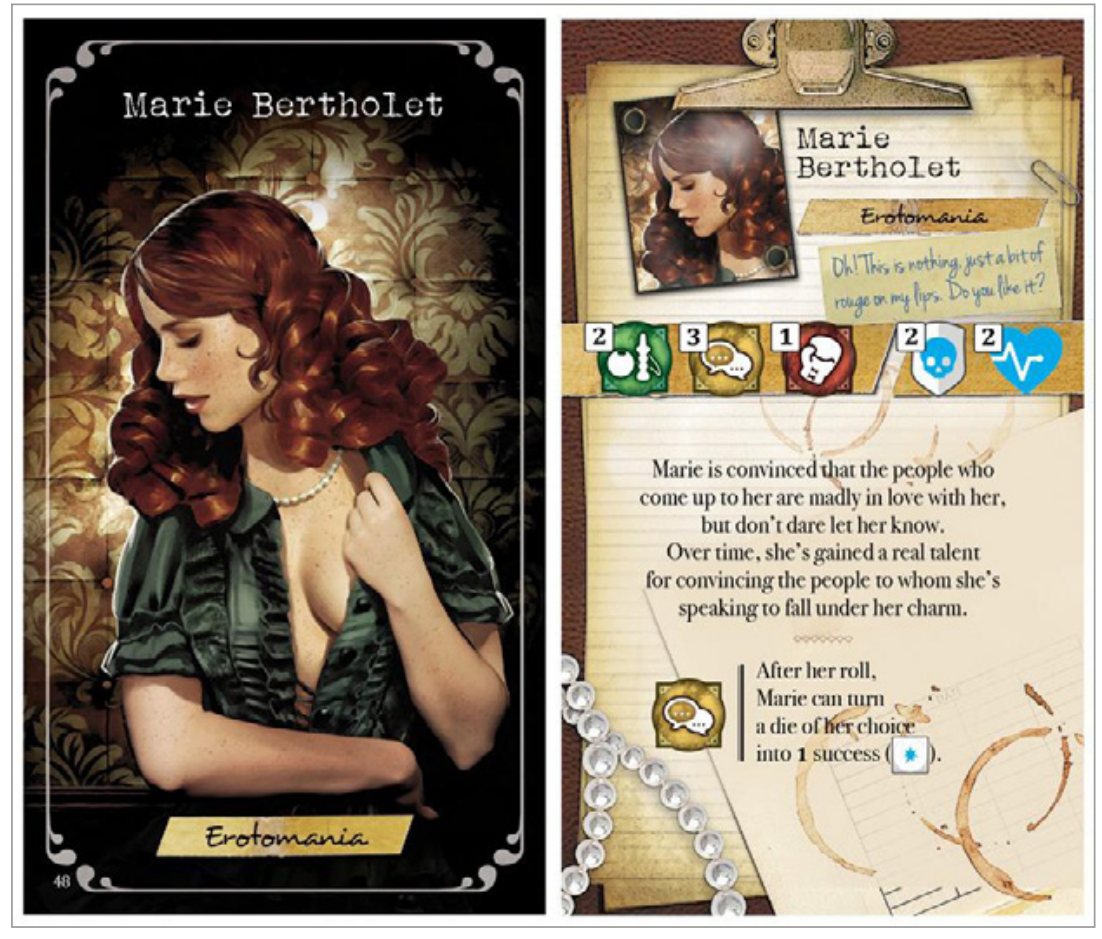

Figura 6 - Carta do receptáculo Marie Bertholet, contendo o número de dados a ser rolado em seus testes, sua resistência, pontos de vida e poder único. Fonte: <https://bit.ly/3gKmMJ3>. Acesso em: 23 out. 2018.

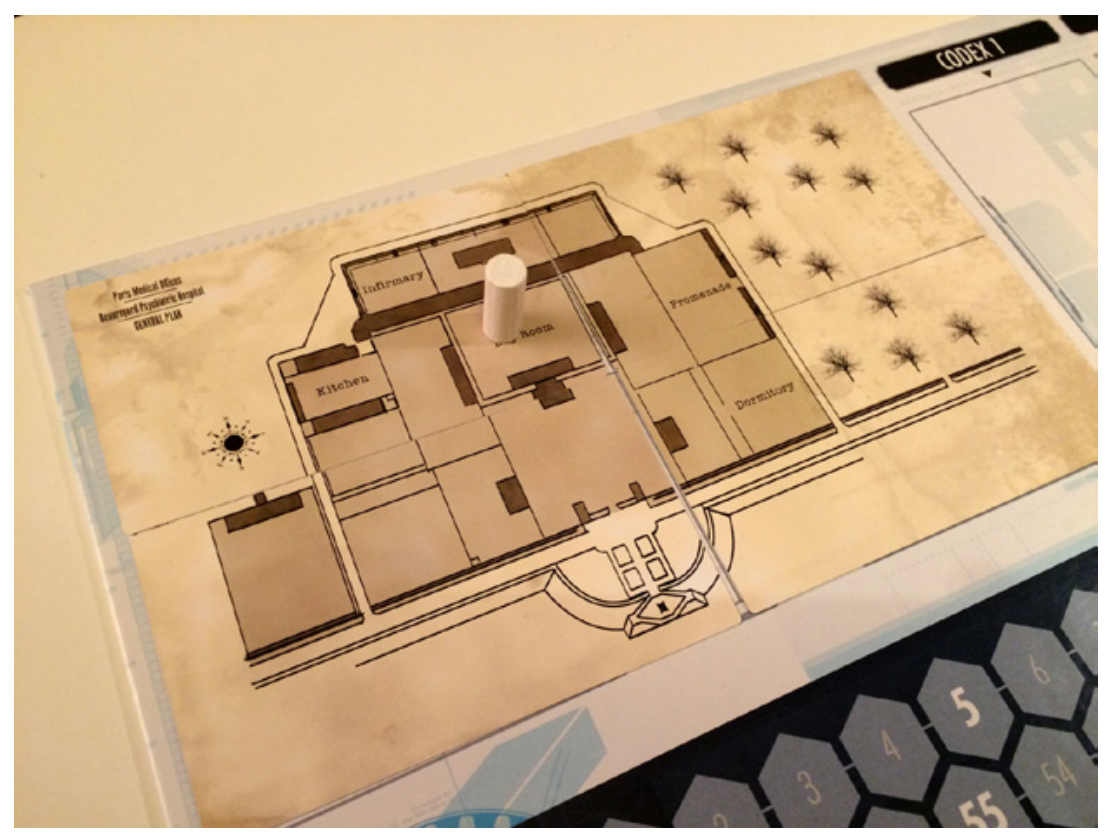

Figura 7 - Planta da missão incluída no jogo base de T.I.M.E. Stories, Asylum, com o token que representa o paradeiro do grupo de jogadores. Fonte: <https://bit.ly/2LtGddH>. Acesso em: 22 abr. 2019. 
- Realizar um teste indicado na carta de localidade em que o jogador se encontra. Nesta carta, a descrição do teste dirá quantos sucessos são necessários para que este seja resolvido. Para isso, o jogador deverá rolar o número de dados de ação da característica requerida pelo teste, que está indicado no verso da sua carta de receptáculo. Tais testes podem trazer diversas vantagens para o grupo: derrotar um oponente, novos itens, localidades secretas, enigmas, dentre outras.

- Certos testes possuem níveis de dificuldades maiores do que outros, medido por escudos. Cada sucesso obtido nas rolagens elimina uma ficha de escudo do teste. Existem diversos tipos de fichas de escudos, com funcionalidades distintas.

- Se o teste em questão for um teste de combate e o jogador rolar um símbolo de caveira em algum dos dados, há um contra-ataque do oponente. Somam-se todos os símbolos de caveiras obtidos nos dados com as fichas de escudo do inimigo que também possuem caveiras.

- Se a resistência do receptáculo for maior ou igual ao número resultado, nada acontece. Porém, se a resistência do receptáculo for menor que o número de caveiras, perde-se um ponto de vida.

- Alguns testes possuem o ícone de um cadeado. Isso significa que os jogadores presentes naquela carta de localidade não poderão se mover até resolvê-lo.

- Mover-se para outra carta da localidade.

- Não realizar nenhuma ação.

Após finalizar a exploração de local, o grupo pode trocar de localidade. O Capitão do Tempo da rodada rola o dado de TUs, que dirá a quantidade de TUs a ser gasta na troca (de 1 a 3 TUs). A nova localidade é revelada e a exploração recomeça.

Conforme o decorrer da missão, os próprios acontecimentos narrados nas cartas de localidade irão ditar a falha 
ou o sucesso do grupo. Em caso de falha, que pode ocorrer por esgotamento de TUs ou pelo desenrolar de decisões equivocadas, os agentes recomeçam a missão sem os itens adquiridos e com uma maior quantidade de TUs disponíveis, mas seu ranqueamento de sucesso decai progressivamente. Em caso de sucesso na missão, os agentes retornam à base da T.I.M.E. e os jogadores vencem o jogo.

\subsection{NARRATIVA}

Em T.I.M.E. Stories, o sistema de mecânicas atua como o proporcionador da história a ser explorada de maneira exemplar, suportando diversas eras e realidades alternativas. Assim como no caso das histórias de detetive, exemplificado pelo autor Henry Jenkins (2004, p. 126, tradução livre), "[...] duas histórias [são contadas] simultaneamente - uma relativamente cronológica (a história da investigação em si) e outra contada radicalmente fora de sequência (os eventos que motivaram e levaram ao assassinato)", em T.I.M.E. Stories, duas temporalidades de narrativa diferentes são exploradas: uma delas, que ocorre na base da agência T.I.M.E., possui características temporais futurísticas e é apresentada no início e no final de cada missão, dando motivação para que os eventos do jogo ocorram. A segunda temporalidade é a da aventura a ser jogada, que pode acontecer em qualquer universo imaginável.

O jogo base inclui a aventura Asylum, que consiste nos acontecimentos de um hospital psiquiátrico localizado em Paris nos anos 20. Várias expansões já foram lançadas, como a The Marcy Case (2015), uma aventura de apocalipse zumbi ocorrida nos Estados Unidos nos anos 90 e Under the Mask (2016), que leva os agentes à era dos faraós do Antigo Egito em 1100 A.C. Tal amplitude de possibilidades narrativas torna T.I.M.E. Stories um jogo incentivador da produção vinda de sua comunidade de fãs. Os próprios jogadores podem desenvolver aventuras com base no sistema de mecânicas fornecido pelo jogo base. 
Em adendo, a forma que a narrativa é apresentada é interativa e imersiva, sendo revelada a cada localidade visitada por meio de cartas. Tais cartas possibilitam que a narrativa seja experienciada de maneira não-linear, promovendo a exploração e a tomada de decisões dos jogadores cooperativamente. Tais decisões, inclusive, geraram consequências positivas ou negativas que podem atrasar ou levar em direção à resolução final da missão.

\subsection{ESTÉTICA}

A estética de T.I.M.E. Stories atua como um elemento unificador das demais partes da tétrade, ao mesmo tempo que reforça as características narrativas do jogo. Os elementos do jogo base que são comuns a todas as missões, como o tabuleiro, o livro de regras, os pinos de personagens, os dados e as fichas apresentam uma estética simplificada, neutra e de ar futurístico, com predominância de tons de azul. Juntamente das cartas da localidade da base, essa é a forma que a linha de narrativa que ocorre na base da agência T.I.M.E. é representada visualmente (Figura 8 ).
Figura 8 - Elementos neutros de T.I.M.E. Stories, que são reutilizados para todas as aventuras.

Fonte: <https://bit.ly/2LpygWU>. Acesso em: 29 out. 2018.

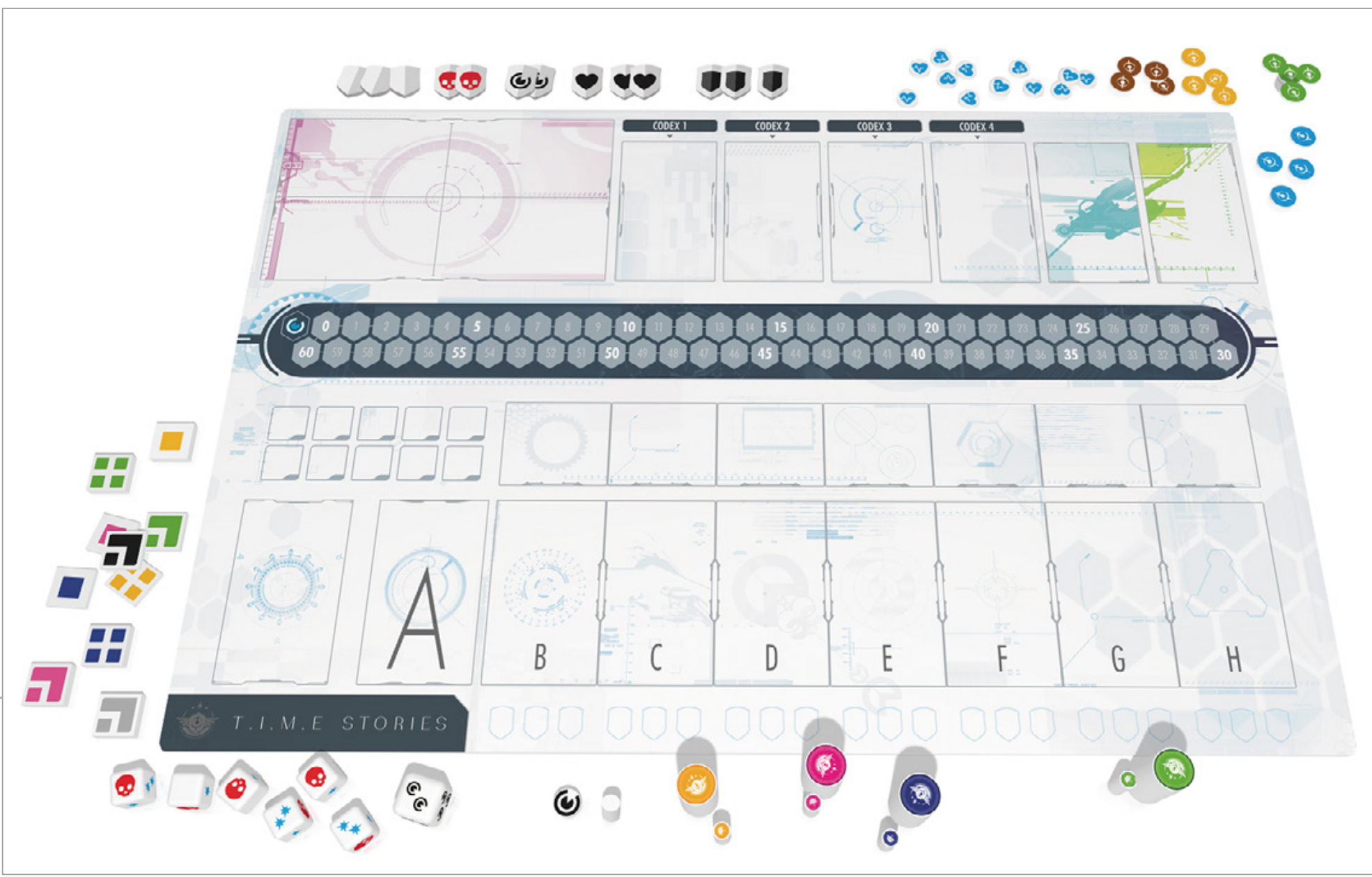


Por outro lado, os elementos específicos de cada aventura, como cartas de receptáculos e de localidades, apresentam estilos de estética diferenciados e marcantes que ilustram a ambientação de cada missão (Figura 9).
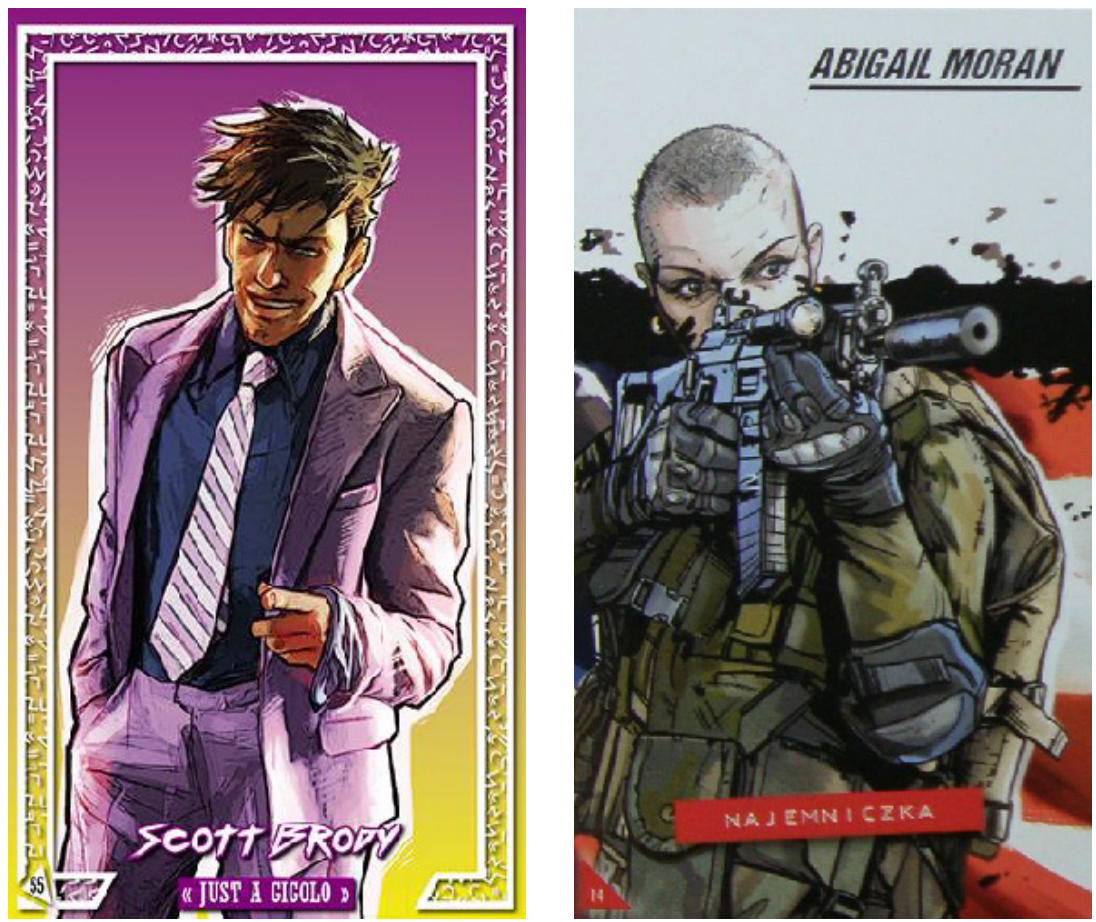

Figura 9 - Cartas de receptáculos, respectivamente, das aventuras Estrella Drive, The Marcy Case, Asylum e Under the Mask, mostrando claramente a diversidade de estilos estéticos adotados para cada missão de T.I.M.E. Stories. Fonte: A autora.
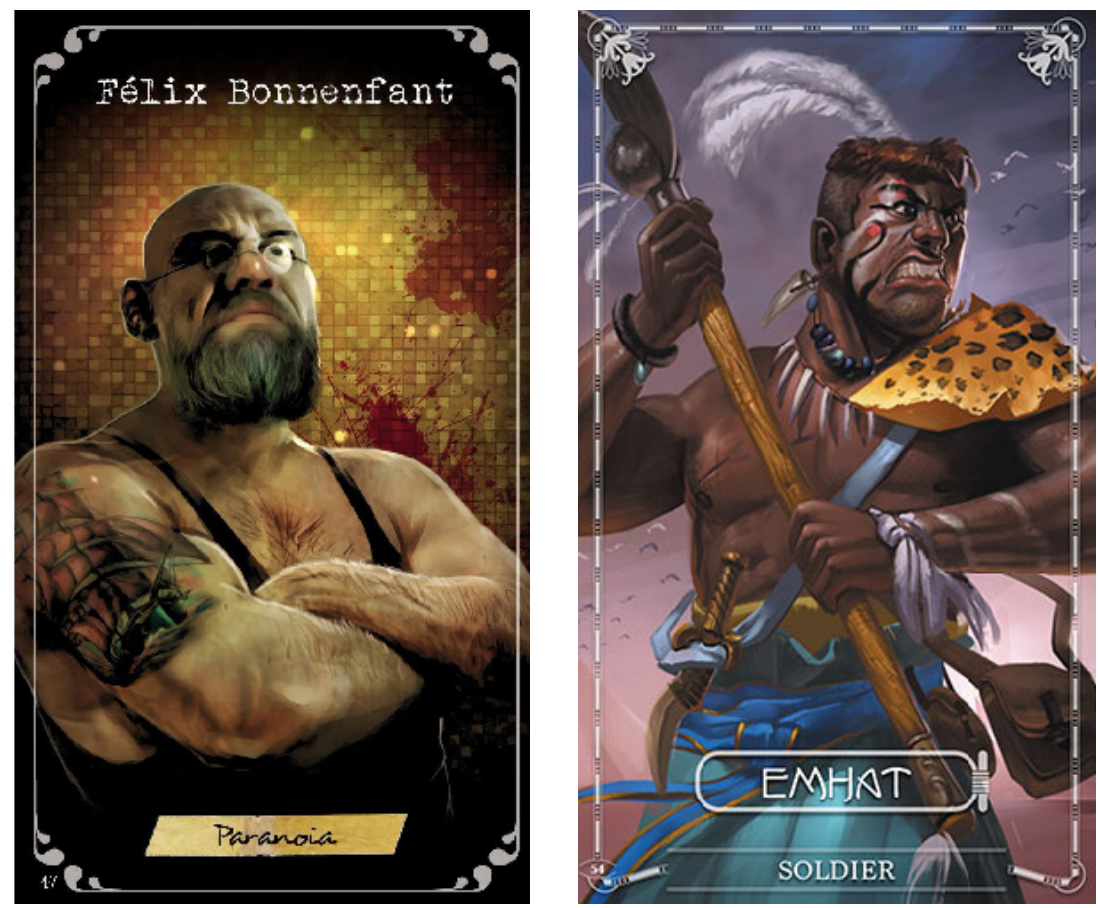
Apesar dos estilos estéticos serem variáveis de acordo com a ambientação, alguns padrões são seguidos por especificidades mecânicas, como as cartas de cada localidade, que ao serem dispostas lado a lado, formam um panorama do ambiente, promovendo imersão narrativa. Ademais, a ilustração presente nestas cartas é significativa, já que, ao serem interpretadas, elas podem dar dicas de informações que os jogadores revelarão ao examiná-las, o que incentiva os jogadores a pensarem narrativamente (Figura 10).

O verso das cartas de localidade, onde estão presentes as informações narrativas e as cartas de itens, também pode conceder informações valiosas por meio de suas ilustrações (Figura 11).
Figura 10 - A carta D da

localidade Day Room da aventura Asylum apresenta uma menina pintando um quadro. Ao se deparar com tal cena, o jogador é instigado a analisar o que a menina está pintando. Portanto, ao verificar o verso da carta, o jogador se depara com uma ilustração detalhada do quadro, que fornece dicas valiosas para o restante da aventura. Fonte: <https://bit.ly/2LysaDO>. Acesso em: 22 abr. 2019.
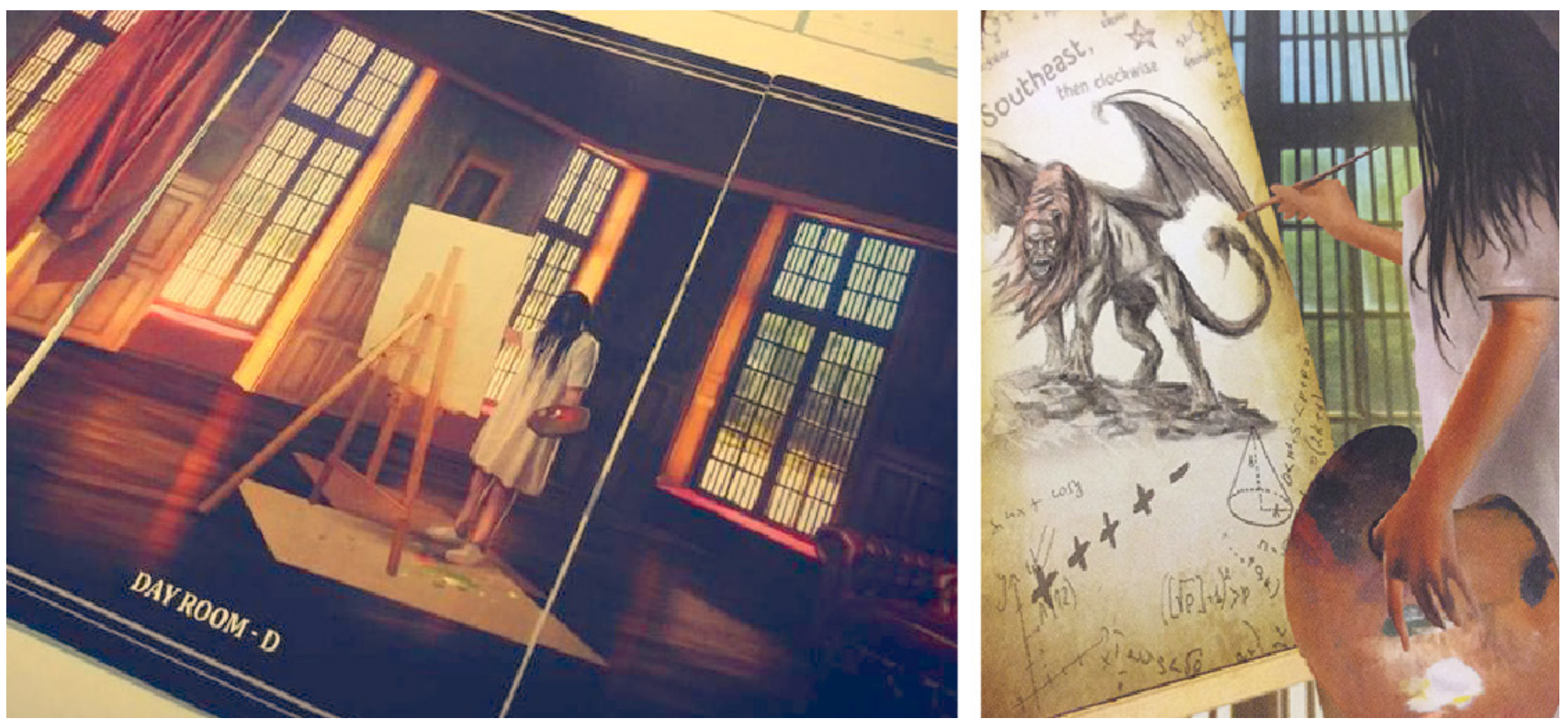

É notável que a estética foi explorada em T.I.M.E. Stories de maneira ideal, realçando e interagindo com os demais aspectos do jogo e, assim, não se limitando apenas a um fator adicional. 


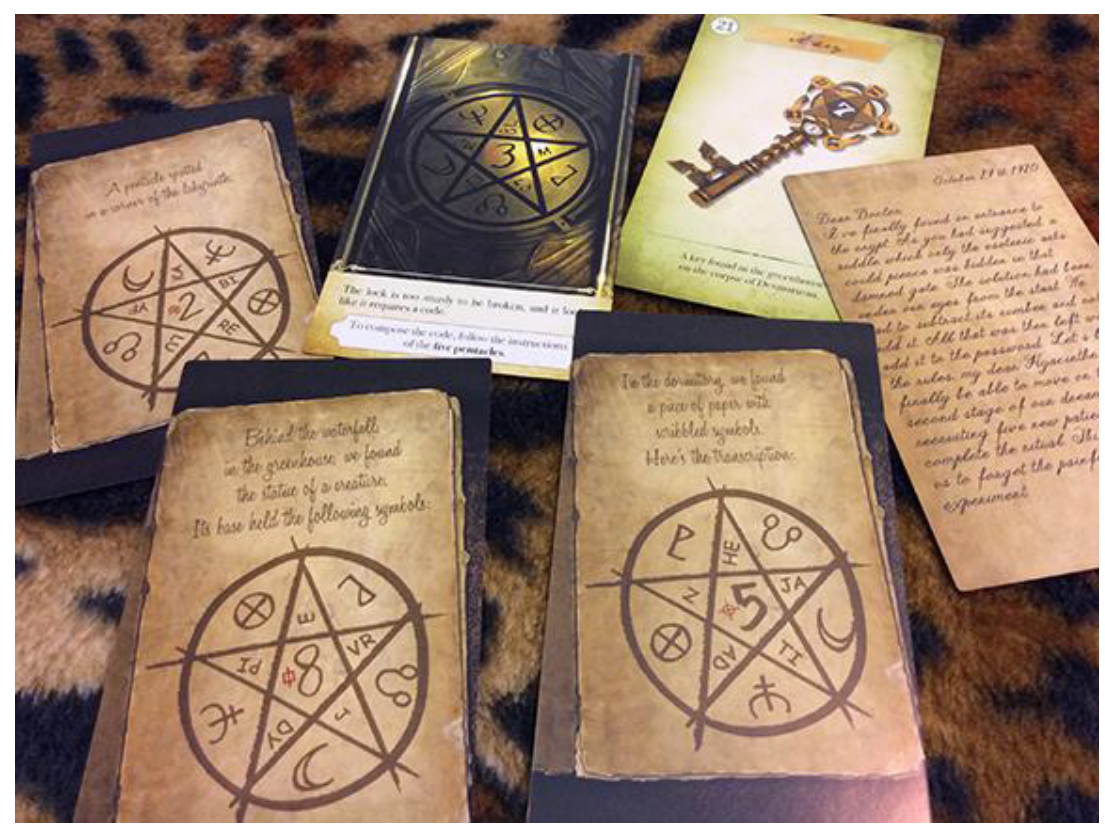

Figura 11 - Verso das cartas de itens adquiridos na aventura Asylum. A interpretação de suas ilustrações leva à resolução de um enigma decisivo. Fonte: $<$ https://bit.ly/3ngwKod>. Acesso em: 29 out. 2018.

\subsection{TECNOLOGIA}

Em T.I.M.E. Stories, os materiais que os jogadores podem manipular são pinos, tokens, dados, fichas e cartas.

- Os pinos atuam como elementos de demarcação de onde os agentes se encontram em cada localidade.

- Os tokens são elementos adquiridos durante a exploração. Certas cartas requeremtokens paraserem desbloqueadas.

- Existem dois tipos de dados: os dados de ação, utilizados em testes para medir o número de sucessos ou caveiras da tentativa de solucioná-los; e o dado de TUs, rolado pelo Capitão do Tempo para determinar quantas TUs foram gastas a cada rodada.

- As fichas possuem diversos propósitos, podendo representar a resistência dos inimigos por meio de escudos, a quantidade de vida dos personagens por meio de corações, e outros recursos, como munição para armas. É válido mencionar que os recursos representados pelas 
fichas variam de acordo com a missão a ser jogada, ou seja, tal material é bem utilizado tecnologicamente.

- Além destes componentes secundários, a jogabilidade é baseada principalmente na revelação e exploração de localidades através do uso de cartas, o que as torna o principal componente tecnológico do jogo.

As cartas de localidade possuem, em sua frente, uma ilustração do cenário em que os agentes se encontram. Um panorama da localidade é formado por uma ilustração contínua ao dispor as cartas na ordem correta. Já o verso das cartas de localidade é utilizado de forma inteligente, assumindo diversas funcionalidades. A mais comum delas é a funcionalidade narrativa, que fornece informações e pistas aos jogadores por meio de acontecimentos interativos na forma de diálogos ou objetos do cenário. O verso das cartas de localidade também pode conter testes de características, explicados anteriormente, ou testes de combate, nos quais um inimigo é apresentado. Por último, também pode-se revelar um enigma em forma de quebra-cabeça, fazendo com que os jogadores precisem interagir fisicamente com as cartas (Figura 12). As cartas também são utilizadas para representar itens, plantas (mapas), receptáculos e demais eventos.

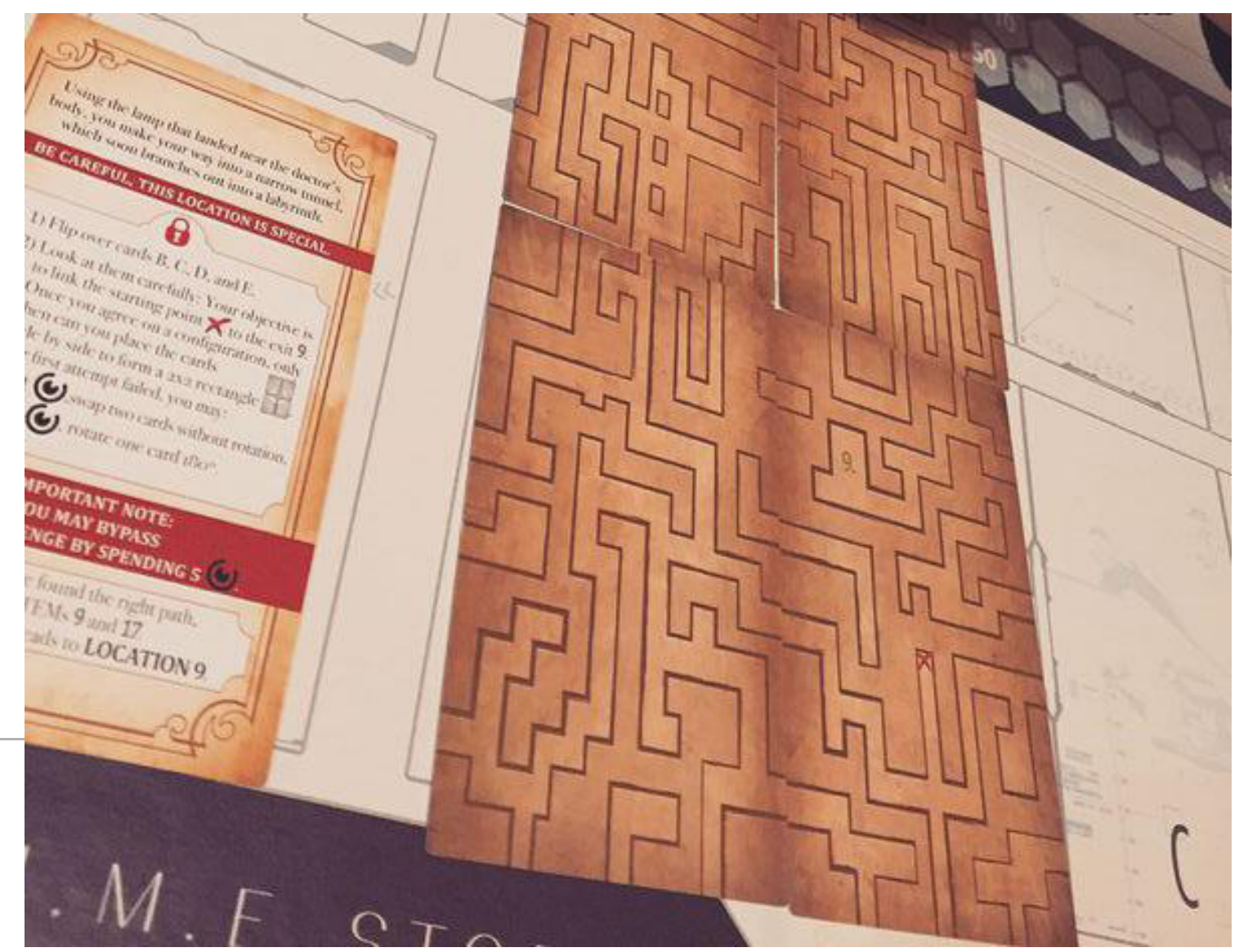

Figura 12 - Quebra-cabeças da aventura Asylum. Os jogadores precisam resolver o labirinto mentalmente, sem mover as cartas até o momento em que possuem certeza de sua solução. Uma dica importante é dada: as cartas podem ser giradas 180 graus. Fonte: <https://bit.ly/2ILjBVd>. Acesso em: 22 abr. 2019. 
O tabuleiro serve como uma grande base para o posicionamento dos elementos do jogo. No canto superior esquerdo, há o espaço designado para as quatro cartas que formam a planta (mapa) da missão. À direita, ficam posicionados os locais para as cartas códex e as cartas de sucesso ou falha da missão. Na porção central do tabuleiro, há um grande marcador de TUs, indicando quanto tempo ainda resta para os agentes concluírem a missão. Abaixo, uma seção quadriculada abriga os tokens adquiridos. Por fim, a grande seção das cartas de localidade possui uma linha superior, onde os jogadores posicionam seus pinos coloridos acima das cartas que gostaram de visitar e uma seção inferior, onde ficam dispostas as cartas de localidade, formando o panorama do cenário. Além disso, existe um local para a adição de escudos de testes embaixo de cada carta. Portanto, o cuidado para que os materiais que compõem a tecnologia de T.I.M.E. Stories fossem compatíveis com os diversos universos a serem explorados no jogo é notável e bem executado.

\subsection{BENCHMARKING}

T.I.M.E Stories é considerado referência no âmbito de jogos de tabuleiro com enfoque em narrativa, reconhecimento justificado pelos vários pontos positivos já citados na presente análise. O motivo da qualidade do jogo encontra-se no fato de que os pontos que compõem a tétrade elementar receberam atenção especial e igualitária. A estética, a tecnologia e a mecânica trabalham juntas para reforçar o enfoque narrativo do jogo, interagindo harmoniosamente entre si. Pode-se perceber essa qualidade quando as decisões tomadas nas missões, requeridas pelas mecânicas, são feitas pelos jogadores através de reflexões de ótica narrativa, por exemplo.

Apesar de suas qualidades, T.I.M.E. Stories divide opiniões dentro do meio de jogadores dedicados ao hobby,

gerando controvérsia. Seus pontos negativos mais criticados pela comunidade são: 
- Há certo abrandamento ou até mesmo ausência de punições aos jogadores nos momentos de falha. Quando um receptáculo morre, por exemplo, o jogador apenas fica sem jogar por sete TUs;

- Relacionado ao ponto anterior, o mecanismo de resetamento força os jogadores a realizarem tentativas repetitivas até que o grupo consiga suceder em uma missão. Tal mecanismo incomoda alguns jogadores, já que a aventura Asylum, por exemplo, dificilmente é completada em apenas uma tentativa. A jogabilidade pode acabar se tornando cansativa e frustrante;

- O valor de rejogabilidade do jogo pode não ser interessante para todos os jogadores. Após finalizar uma aventura, todos os componentes do grupo já saberão como solucioná-la;

- Um ponto negativo secundário é que o jogo ainda não foi traduzido para o português, dependendo totalmente de conhecimentos em língua estrangeira para compreender sua narrativa.

Ao final da análise, conclui-se que T.I.M.E. Stories é um jogo que comprova com excelência que jogos de tabuleiro podem promover narrativas.

\section{CONSIDERAÇÕES FINAIS}

As análises benchmark a partir da tétrade elementar de Schell examinaram dois jogos de tabuleiro com enfoque narrativo: Scotland Yard e T.I.M.E. Stories. Estes jogos foram esmiuçados em relação aos seus aspectos de mecânica, narrativa, estética e tecnologia, além de terem seus pontos positivos e negativos apontados.

Tais análises foram de suma importância para a coleta de insumos utilizados no processo de game design posteriormente executado, culminando na pré-produção de "Industrial Cases", um jogo de tabuleiro com enfoque narrativo e temas de mistério e investigação. 


\section{REFERÊNCIAS BIBLIOGRÁFICAS}

CARDIA, Wagner; GRINGS, Zaniel. Benchmarking -

Mais do que um conceito da moda. Atualizado em:

19 ago. 2015. Disponível em: <http://home.furb.br/

wilhelm/COMPETIV/>. Acesso em: 22 abr. 2019.

JENKINS, Henry. Game design as narrative

architecture. 2004. Disponível em: <http://

electronicbookreview.com/essay/game--design-as-

narrative-architecture/> Acesso em: 22 abr. 2019.

SCHELL, Jesse. A arte do game design: o livro original.

Tradução de: Edson Furmankiewicz. São Paulo: Elsevier, 2011.

ULIANO, Marcelle. Industrial Cases: Design da pré-produção

de um jogo de tabuleiro com enfoque narrativo. 2018. 55

f. Monografia (Bacharelado em Design Gráfico) - Centro

de Artes, Universidade Federal de Pelotas, Pelotas, 2018. 